\title{
Meandering Dispersion Model Applied to Air Pollution
}

\author{
Gervásio A. Degrazia, Andréa U. Timm, Virnei S. Moreira, Débora R. Roberti \\ Universidade Federal de Santa Maria/UFSM \\ Brazil
}

\section{Introduction}

Generally in stable conditions, during situations of low wind speed $\left(\overline{\mathrm{u}} \leq 1-2 \mathrm{~ms}^{-1}\right)$, low-frequency horizontal wind oscillations (meandering) are observed in a nocturnal Planetary Boundary Layer (PBL). The study of low wind speed conditions is of interest, partly because the simulation of airborne pollutant dispersion in these conditions is rather difficult. In fact, most of the existing regulatory dispersion models become unreliable as $\bar{u}$ approaches zero, so that their application is generally limited to $\left(\overline{\mathrm{u}}>2 \mathrm{~ms}^{-1}\right)$. The meandering movements are clearly distinct from those associated to a full developed turbulence, which are responsible for the pollutants dispersion in a PBL. Even when the stability reduces the vertical dispersion and the instantaneous plume may be thin, meandering disperses the plume over a rather wide angular sector. As a consequence, any air pollution operational dispersion model to be reliable must take into account the transport effect provocated by the meandering.

Transport phenomenon in turbulence, including the diffusion of passive scalars and the dispersion of pollutants in the PBL, are controlled by the advection processes associated with the action of stochastic velocity fluctuations in time and space. As a consequence, a Lagrangian description following the movement of infinitesimal fluid particles, as they are carried by the velocity turbulent fluctuations, is conceptually correct and from practical point of view useful for describing turbulent transport (Yeung, 2002).

Lagrangian stochastic particle models are powerful computational tools for the investigation of the atmospheric dispersion process (Rodean, 1996). In these models, the fluid particle displacements are produced by stochastic velocities and the movement evolution of a particle can be considerate a Markov process (Wang, 1945), in which past and future are statistically independent when the present is known. This method is based on Langevin equation, which is derived from the hypothesis that the velocity is given by the combination between a deterministic and a stochastic term (Chandrasekhar, 1943). Each fluid particle moves taking into account the transport due to the mean wind velocity and the turbulent fluctuations of the wind velocity components. From the spatial distribution of the particles it is possible to determine the pollutant concentrations. The implementation of the Lagrangian stochastic dispersion model in air pollution problems permits to take into account complex situations such as turbulent flows generated above inhomogeneous topo-graphy (different terrains) (Carvalho et al., 2002), in non-stationary situations associated with the evolutionary transition 
periods of the PBL (sunset transition period) and low wind speed conditions which for many places in the world occur for a substantial percentage of time (Oettl et al., 2001). Concerning this last complexity, it is important to note that in low wind velocity situations, particularly during stable conditions, the turbulent dispersion in the PBL is poorly described. As a consequence, the occurrence of low wind speed is generally considered the most critical situation associated with the air pollution dispersion problem.

The aim of this chapter is to report a turbulence parameterization that can be employed in Lagrangian stochastic dispersion models to describe the air pollution dispersion in the situation of low wind velocity stable conditions. This specific parameterization employs an observational value for the meandering period and turbulent velocity variances and decorrelation time scales varying with height for a stable boundary layer. Therefore, are used two classical approaches to obtain the turbulent velocity variances and the decorrelation time scales. The first turbulence approach used in this study was derived by Degrazia et al. (2000) utilizing Taylor statistical diffusion theory while the second one was developed by Hanna (1982). Degrazia et al. (2000) turbulence approach is based on the observed turbulent velocity spectra while Hanna (1982) approach is based on analyses of field experiments, theoretical considerations and second-order closure model.

An additional aim is to incorporate this new parameterization for the meandering dispersion phenomenon in a numerical Lagrangian stochastic particle model to simulate the dispersion of air pollution in a low wind velocity stable boundary layer. The Lagrangian particle model employed in the present investigation is constituted by a system of two coupled Langevin equations describing the meandering dispersion associated to the lateral and longitudinal components of the wind velocity fluctuations. This dispersion model is based on the so-called Thomson simplest solution and can be applied to more general case of inhomogeneous turbulence. The horizontal coupling, occurring between the lateral and longitudinal velocity components, reproduces the meandering enhanced air pollution transport.

Finally, the observed concentration data employed in the comparison with the coupled Lange-vin equations model, incorporating Degrazia et al. (2000) and Hanna (1982) approaches, were obtained from the low wind speed experiment performed in a stable boundary layer from the series of field observations conducted at the Idaho National Engineering Laboratory - INEL.

\section{The SCLE dispersion model}

Simulating the dispersion of contaminants in low wind speed stable conditions is a difficult physical task. In such situations, the airborne contaminants are dispersed over rather wide angular sectors and therefore it is no longer possible to establish a definite mean wind direction since low-frequency horizontal wind oscillations start to dominate and diffusion of contaminants in the PBL becomes controlled by these degrees of freedom, characterized by low frequencies (large characteristic time associated with the meandering period). The horizontal meandering of a flow occurs when the wind speed presents a threshold low value and the low-frequency horizontal wind oscillations generate autocorrelation functions of the horizontal wind components showing a looping behavior evidenced by the presence of accentuated negative lobes (Anfossi et al., 2005; Oettl et al., 2005). This oscillatory character associated with the meandering phenomenon and consequently the presence of large negative lobes in the observed autocorrelation functions were recently explained as an 
intrinsic property of atmospheric flows occurring in weak horizontal turbulent momentum flux conditions (Goulart et al., 2007).

The low wind speed autocorrelation functions of the horizontal wind components displaying an oscillation behavior and the presence of large negative lobes can be very well fitted by the following relationship

$$
R(\tau)=e^{-p \tau} \cos (q \tau)
$$

where

$$
p=\frac{1}{\left(m^{2}+1\right) T_{L u, v}}
$$

and

$$
q=\frac{m}{\left(m^{2}+1\right) T_{L u, v}} .
$$

The functional form as given by the Eqs. (1), (2) and (3) is composed of the product of the classical exponential function (representing the autocorrelation function for a fully developed turbulence) by the cosine function (describes the meandering phenomenon associated with the observed low frequency horizontal wind oscillations) (Frenkiel, 1953). The Frenkiel function (Eq. (1)) is a hybrid formula described in terms of $\mathrm{T}_{\mathrm{Lu}, \mathrm{V}}$, the local horizontal Lagrangian time scale for a fully developed turbulence, and $\mathrm{m}$, the loop parameter which controls the meandering oscillation frequency associated with the horizontal wind. It is worth noting that large $\mathrm{m}$ values characterize the dominant presence of the meandering phenomenon in comparison with the fully developed turbulence.

Anfossi et al. (2006) proposed a system of two coupled Langevin equations (SCLE) to describe the contaminants dispersion in meandering conditions. Therefore, the following system of equations describes the dispersion in low wind speed conditions

$$
d u=\{-p(u-\bar{u})-q(v-\bar{v})\} d t+\sqrt{2 p d t} \sigma_{u} \xi^{u}
$$

and

$$
d v=\{q(u-\bar{u})-p(v-\bar{v})\} d t+\sqrt{2 p d t} \sigma_{v} \xi v
$$

where $\mathrm{u}$ and $\mathrm{v}$ are the horizontal components of the wind velocity fluctuations, $\xi u$ and $\xi v$ are random Gaussian variables having zero mean and unit variance, $\sigma_{u}$ and $\sigma_{v}$ are standard deviations of the horizontal wind components. It is important to note that Eqs. (4) and (5) are valid assuming horizontal homogeneous conditions (Anfossi et al., 2006).

For the vertical component of the velocity fluctuation $\mathrm{w}$ we solve the Langevin equation accor-ding to the usual LAMBDA model (Anfossi et al., 2006; Thomson, 1987)

$$
d w=a_{i}(z, w)+b_{0}(z) d W_{j}
$$

where $d W_{j}$ is the incremental Gaussian Wiener process (with zero mean and variance $d t$ ), $b_{0}(z)=\sqrt{2 \sigma_{w}^{2} / T_{L w}}\left(\sigma_{w}^{2}\right.$ is the vertical turbulent velocity variance and $\mathrm{T}_{\mathrm{Lw}}$ is the vertical local Lagrangian time scale) and $\mathrm{a}_{\mathrm{i}}(\mathrm{z}, \mathrm{w})$ is computed by solving the Fokker-Planck equation associated with Eqs. (4) and (5) using a PDF of Gram-Chalier type truncated to the third-order (Ferrero \& Anfossi, 1998). 
The position of each particle, at each time step, is obtained by the numerical integration of Eqs. (4) and (5) and (6) and the following equation:

$$
d x_{i}=u_{i} d t
$$

where $i=1,2,3, x_{i}$ is the position vector of each particle, $u_{i}$ is its corresponding Lagrangian velocity vector. Therefore, to describe the diffusion of passive scalars in the PBL the Langevin equation is integrated according to the rules of the Ito calculus (Gardiner, 1997), which was developed to get solutions of the stochastic differential equations.

\section{Turbulence parameterization for modeling meandering effects in the stable PBL}

The fundamental parameters to reproduce meandering transport effects, employing the Eqs. (4) and (5), are the quantities $\mathrm{m}, \sigma_{u, v}$ and $\mathrm{T}_{\mathrm{Lu}, \mathrm{v}}$ which define the Eqs. (1), (2), (3), (4) and (5). In this section the values of these physical parameters will be computed.

In PBL turbulent dispersion models the selection of an adequate parameterization plays a fundamental role to evaluate the contaminants concentration in the atmosphere. Thusly, the efficiency of each approach to reproduce correctly the contaminants concentration field depends on the manner turbulent parameters are related to physical properties of the PBL. In the specific case of parameterization of the enhanced horizontal diffusion of passive scalars, controlled by the meandering phenomenon, the variables $\mathrm{p}$ and $\mathrm{q}$ need to be introduced into Eqs. (4) and (5). Analyzing the Eqs. (1), (2) and 3) we can define the following meandering period (Anfossi et al., 2005).

$$
T_{*}=\frac{2 \pi\left(m^{2}+1\right) T_{L u, v}}{m},
$$

from which can be obtained a relation for $\mathrm{m}$ given by (Carvalho et al., 2006)

$$
m=\frac{T_{*}+\sqrt{T_{*}^{2}-16 \pi^{2} T_{L u, v}^{2}}}{4 \pi T_{L u, v}}
$$

As seen in Eq. (9), this formula for the loop parameter, defines $m$ as a quantity that can be estimated from the meandering period $\mathrm{T}_{*}$ and of the local horizontal time scale associated with a fully developed turbulence $T_{\mathrm{Lu}, \mathrm{v}}$. On the other hand, analyzing Eq. (9) it is possible to notice that the presence of large values for the local turbulent time scales impede the increasing of $\mathrm{m}$ and consequently the meandering reinforced transport tends to vanish in the PBL. Time series of sonic anemometer wind speeds were analyzed by Anfossi et al. (2005). These observational data suggest that the mean magnitude of the meandering period is of the order of $\mathrm{T}_{*} \cong 2000 \mathrm{~s}$.

\subsection{Turbulence parameterization derived by Degrazia et al. (2000) and Hanna (1982)}

It is possible to relate turbulent parameters (wind velocity standard deviations $\sigma_{u, v, w}$ and Lagrangian decorrelation time scales $\mathrm{T}_{\mathrm{Lu}, \mathrm{v}, \mathrm{w}}$ ) to spectral distribution of turbulent kinetic energy (TKE). Following this approach, Degrazia et al. (2000) developed expressions for the wind velocity variances and Lagrangian decorrelation time scales. The velocity variances were obtained directly from the integration of the turbulence velocity spectra (Caughey \& Palmer, 1979). On the other hand, the Lagrangian decorrelation time scales were derived 
from the peak wavelength of the turbulent velocity spectra (Caughey, 1982). Therefore, the turbulent velocity variances $\left(\sigma_{u, v, w}\right)$ and the local turbulent time scales $\left(\mathrm{T}_{\mathrm{Lu}, \mathrm{v}, \mathrm{w}}\right)$ for a stable boundary layer are given respectively by the following expression (Degrazia et al., 2000)

$$
\sigma_{u, v, w}^{2}=\frac{2.32 c_{u, v, w} \phi_{\epsilon}^{2 / 3} u_{*}^{2}}{\left[\left(f_{m}^{*}\right)_{u, v, w}^{s}\right]^{2 / 3}}
$$

and

$$
T_{L u, v, w}=\frac{z}{\sqrt{c_{u, v, w}}}\left\{\frac{0.059}{\left[\left(f_{m}^{*}\right)_{u, v, w}^{s}\right]^{2 / 3}\left(\phi_{\epsilon}^{s}\right)^{1 / 3} u_{*}}\right\}
$$

where $\mathrm{z}$ is the height above the surface, $c_{u, v, w}=\alpha_{u, v, w} \alpha_{u}(2 \pi k)^{-2 / 3}$ with $\mathrm{k}=0.4$ (von karman constant), $\alpha_{u}=0.5 \pm 0.05$ and $\alpha_{u, v, w}=1,4 / 3,4 / 3$, respectively (Champagne et al., 1977; Sorbjan, 1989). For a shear-dominated stable PBL the adimensional dissipation rate $\phi_{\epsilon}^{s}=\epsilon_{s} k z / u_{*}^{3}$ can be written as $\phi_{\epsilon}^{S}=1.25(1+3.7 z / \Lambda)$ where $\Lambda$ is the local Obukhov length given by $\Lambda=L(1-z / h)^{\left(1.5 \alpha_{1}-\alpha_{2}\right)}$, with $h$ being the height of the turbulent stable PBL and $L$ is the surface Obukhov length. Furthermore, for a shear-dominated stable PBL, the local friction velocity is defined by $u_{*}=\left(u_{*}\right)_{0}(1-z / h)^{\alpha_{1} / 2}$, where $\left(u_{*}\right)_{0}$ is the surface friction velocity and $\alpha_{1}=1.5$ and $\alpha_{2}=1.0$ (Nieuwstadt, 1984). Finally, the reduced frequency of the stable horizontal spectral peaks is provided by the following relation $\left(f_{m}^{*}\right)_{u, v, w}^{S}=\left(f_{m}\right)_{(u, v, w) s}^{n}(1+$ $3.7 z / \Lambda)$ where $\left(\mathrm{f}_{\mathrm{m}}\right)_{\mathrm{us}}^{\mathrm{n}}=0.045,\left(\mathrm{f}_{\mathrm{m}}\right)_{\mathrm{vs}}^{\mathrm{n}}=0.16$ and $\left(\mathrm{f}_{\mathrm{m}}\right)_{\mathrm{ws}}^{\mathrm{n}}=0.33$ are the frequencies of the spectral peaks in the surface for neutral conditions (Olesen et al., 1984; Sorbjan, 1989).

Based on analyses of field experiments (Hanna, 1981; 1968; Kaimal, 1976), theoretical consi-derations (Irwin, 1979; Panofsky et al., 1977) and second-order closure models (Wyngaard et al., 1974), Hanna (1982) proposed the following turbulence parameterization for the turbulent velocity variances $\left(\sigma_{u, v, w}\right)$ and the local turbulent time scales $\left(\mathrm{T}_{\mathrm{Lu}, v, \mathrm{w}}\right)$ :

$$
\frac{\sigma_{u}}{\left(u_{*}\right)_{0}}=2\left(1-\frac{z}{h}\right)
$$

and

$$
\begin{gathered}
\frac{\sigma_{w}}{\left(u_{*}\right)_{0}}=\frac{\sigma_{v}}{\left(u_{*}\right)_{0}}=1.3\left(1-\frac{z}{h}\right), \\
T_{L u}=0.15 \frac{h}{\sigma_{u}}\left(\frac{z}{h}\right)^{0.5}, \\
T_{L v}=0.07 \frac{h}{\sigma_{v}}\left(\frac{z}{h}\right)^{0.5}
\end{gathered}
$$

and

$$
T_{L w}=0.10 \frac{h}{\sigma_{w}}\left(\frac{z}{h}\right)^{0.8}
$$

From Eqs. (10) and (11), it can be seen that the turbulent velocity variances and the local Lagrangian time scales associated with the fully developed turbulence in the shear-dominated stable turbulent flow in PBL are formulated in terms of a similarity theory and expressed by 
three fundamental parameters associated with the turbulence in a PBL; the friction velocity, the adimensional dissipation rate and the reduced frequency of the horizontal spectral peaks. On the other hand, Eqs. (12), (13), (14), (15) and (16) are expressed in terms of a similarity theory and described by two fundamental scales, the friction velocity $\left(\mathrm{u}_{*}\right)$ and the height of the turbulent stable PBL.

Therefore, using Eq. (9), with $\mathrm{T}_{*} \cong 2000 \mathrm{~s}$ and $\mathrm{T}_{\mathrm{Lu}, \mathrm{v}}$ given by the Eqs. (11), (14) and (15), the low-frequency horizontal wind oscillation effects can be parameterized and introduced into Eqs. (4) and (5) to simulate the observed dispersion of passive scalars, caused by the meandering transport in the stable PBL.

\section{Meandering dispersion simulation}

The results of the proposed model are compared with the concentration data collected under stable conditions in low wind speeds over flat terrain at the Idaho Engineering Laboratory (INEL). These observed results have been published in a U.S. National Oceanic and Atmos-pheric Administration (NOAA) report (Sagendorf \& Dickson, 1974). Because of wind direction large variability associated with the meandering phenomenon, a full $360^{\circ}$ sampling grid was implemented. Arcs were laid out at radii of 100, 200 and $400 \mathrm{~m}$ from the emission point source. Samplers were placed at intervals of $6^{\circ}$ on each arc for a total of 180 sampling locations. The receptor height was $0.76 \mathrm{~m}$. The tracer $\mathrm{SF}_{6}$ was released at a height of $1.5 \mathrm{~m}$. The $1 \mathrm{~h}$ average concentrations were determined by means of an electron capture gas chromato-graphy. Wind speeds measured at levels 2, 4, 8, 16, 32 and $61 \mathrm{~m}$ were used to calculate the coefficient for the exponential wind vertical profile. According to Brusasca et al. (1992) and Sharan \& Yadav (1998) the roughness length used was $\mathrm{z}_{0}=0.005 \mathrm{~m}$. The Monin-Obukhov length $\mathrm{L}$ and the friction velocity $\mathrm{u}_{*}$ were not available for the INEL experiment but can be roughly estimated by different formulations. Then, $\mathrm{L}$ may be calculated from an empirical formulation suggested by Zannetti (1990) and the stable turbulent PBL height $\mathrm{h}$ was determined according to expression derived by Zilitinchevick (1972).

INEL observed concentrations, $\chi_{m}\left(m^{-2}\right)$, were normalized according to the following relation (Sagendorf \& Dickson, 1974)

$$
\chi_{m}=C_{m} \frac{U_{4}}{Q},
$$

where $C_{m}$ is the dimensional concentration expressed in $\mathrm{gm}^{-3}, \mathrm{U}_{4}$ is the mean wind speed at $4 \mathrm{~m}$ and $\mathrm{Q}$ is tracer emission rate $\left(\mathrm{gs}^{-1}\right)$. Consequently, predicted concentrations are for the INEL experiments expressed in $\left(\mathrm{m}^{-2}\right)$.

For the simulations, the turbulent flow field is considered as inhomogeneous in the vertical direction and the transport is performed by the longitudinal component of the mean wind velocity. In the simulations the horizontal domain was determined according to sampler distances and the vertical domain was set equal to the observed PBL height $h$. The emission point source was localized at the domain centre. The time step was maintained constant and equal to $\Delta t=0.5 \mathrm{~s}$ during the simulations. The magnitude of this time step is of the order of the time scales of Kolmogorov's turbulent energy spectrum inertial subrange. Furthermore, this value of $\Delta t$ performs the following inequality $\Delta t<<T_{L}$. This condition ensures that the turbulent velocities can be considered a Markov process (Rodean, 1996). For each simulation, the number of particles released was $10^{6}$. In the case of the INEL experiments, the cells of 
concentration at ground-level have a vertical dimension of $\Delta z=3 m$ (Anfossi et al., 2006). On the other hand, the horizontal dimensions were computed from the following relation

$$
\Delta x=\Delta y=\frac{2 \pi r}{N_{a n g}},
$$

where $r$ is the arc radius and $N_{\text {ang }}=60$ is the number of samplers per arc. This way of computing the cell size covers all the compass at the three radii without significant overlapping. From these criteria results $\mathrm{dx}=10.47 \mathrm{~m}$, dy $=20.93 \mathrm{~m}$ and $\mathrm{dz}=41.87 \mathrm{~m}$ for the three arcs res-pectively. The simulated concentrations were obtained by counting the number of particles in volumes generated from the vertical and horizontal dimensions above presented.

\section{Results and discussion}

The performance of the SCLE model, employing the meandering parameterization for $\mathrm{u}$ and v components as given by the Eqs. (9), (10), (11), (12), (13), (14) and (15) is shown in Figu-res 1 to 6 and in Table 1. Figs. 1 and 2 show some typical simulation results obtained with the SCLE model employing Degrazia et al. (2000) turbulence parameterization. On the other hand, Figs. 3 and 4 show these same results reproduced with the SCLE model utilizing Hanna (1982) turbulence approach. Figs. 1 and 3 refer to experiment 8 , which is characterized by a plume that spreads horizontally over a wide angular sector (one having the widest horizontal plume spread), meaning that the tracer is collected at all angles. The results of the simulations show that the SCLE model containing (Degrazia et al., 2000) and Hanna (1982) turbulence parameterization is able to reproduce the dispersion of the contaminants plume over all the $360^{\circ}$. Concerning to the environmental effects of air contaminants released in the PBL, the estimation of the location in which the maximum concentration occurs is a fundamental data. Regarding this information, the maximum concentration for experiment 8 at $400 \mathrm{~m}$ is approxi-mately well reproduced by the SCLE model using Degrazia et al. (2000) and Hanna (1982) parameterization. Observing Figs. 2 and 4, we can see that the SCLE model with the Degrazia et al. (2000) and Hanna (1982) turbulence approach simulates fairly well the observed maximum concentrations for experiment 6 at 100, 200 and $400 \mathrm{~m}$.

In addition, to obtain a global evaluation about of the quality of the simulations that were made using the meandering parameterization, the following statistical indices have been computed at each arc, for the ten INEL experiments: concmax, top5 and $\mathrm{S}_{\mathrm{y}}$. Concmax $\left(\mathrm{m}^{-2}\right)$ is the maximum ground-level concentration, top $5\left(\mathrm{~m}^{-2}\right)$ refers to the mean of the 5 highest measured and computed ground-level concentration and $S_{y}=\sqrt{\sum_{i=1}^{N}\left(\vartheta_{i}-\bar{\vartheta}\right)^{2} / \sum_{i=1}^{N} \chi_{i}}$, where $\vartheta_{i}$ are the sampler angles and $\bar{\vartheta}$ their average value (weighted with the concentrations). Considering the INEL experiments, the Figs. 5 and 6 show the results of these statistical indices (concmax, top5 and $\mathrm{S}_{\mathrm{y}}$ ) obtained from the Eqs. (4) and (5) employing the meandering parameterization and respectively Degrazia et al. (2000) and Hanna (1982) turbulence approach. Figs. 5 (a,b and c) (Degrazia et al. (2000) turbulence approach) and Figs. 6 (a,b and c) (Hanna (1982) turbulence approach) show respectively the scatter diagram between observed and predicted concmax, top 5 and $S_{y}$ values. Observing these figures it is possible to notice that there is a certain data spread, however this scattering is not sufficient to avoid a reasonable alignment in relation to the straight of perfect agreement. 

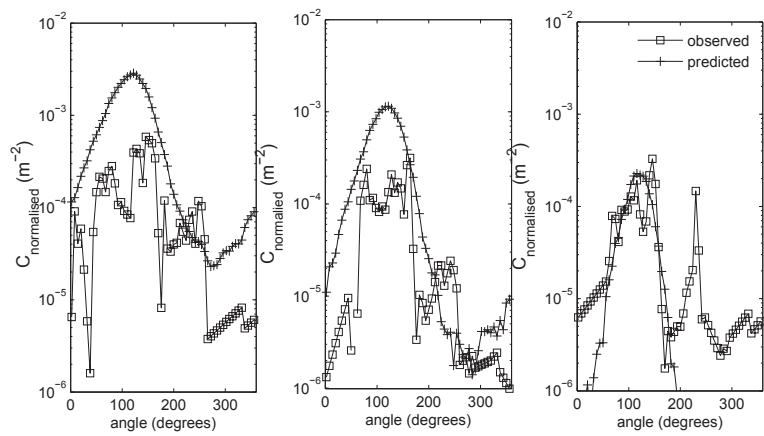

Fig. 1. Normalized ground level concentration $\left(\mathrm{m}^{-2}\right)$ for experiment 8 at 100, 200 and $400 \mathrm{~m}$ as a function of the sampler angles for (Degrazia et al., 2000) turbulence parameterization. Open squares indicate observed concentrations and crosses indicate simulated concentrations.
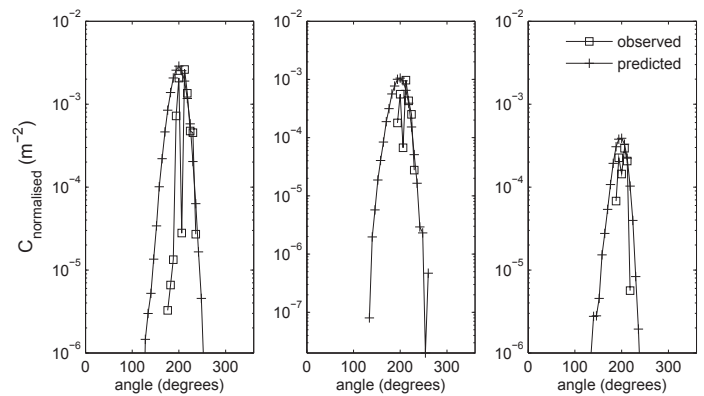

Fig. 2. As Fig. 1 but for experiment 6.
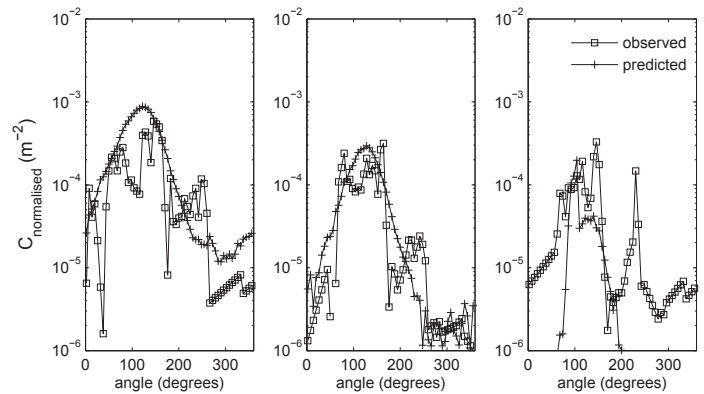

Fig. 3. Normalized ground level concentration $\left(\mathrm{m}^{-2}\right)$ for experiment 8 at 100, 200 and $400 \mathrm{~m}$ as a function of the sampler angles for Hanna (1982) turbulence parameterization. Open squares indicate observed concentrations and crosses indicate simulated concentrations.

Table 1 shows the results of the statistical analysis made with observed and predicted values of peak concentration $(n=30)$. Furthermore, this Table presents a comparison between SCLE 

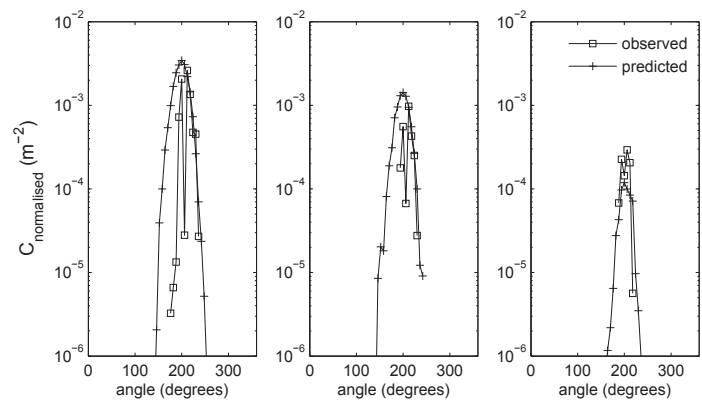

Fig. 4. As Fig. 3 but for experiment 6.

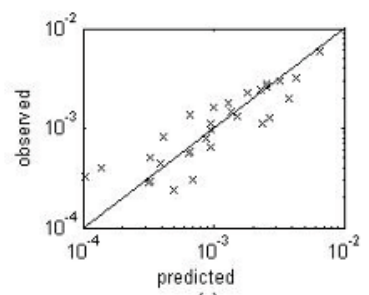

(a)

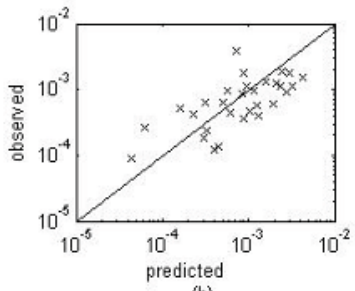

(b)

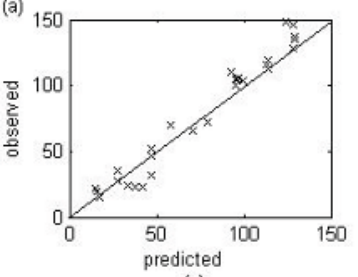

(c)

Fig. 5. Plot of (a) concmax, (b) top5 and (c) Sy calculated with SCLE model utilizing the Degrazia et al. (2000) turbulence parameterization. X-axis shows predicted values whereas observed values are on the Y-axis.

model employing the parameterization (Eqs. (9), (11), (14) and (15)) and other three models (Oettl et al., 2001; Sagendorf \& Dickson, 1974; Sharan \& Yadav, 1998).

The statistical indices are suggested by Hanna (1989):

NMSE $=\overline{\left(C_{o}-C_{p}\right)^{2}} / \overline{C_{o} C_{p}}$ (Normalized Mean Square Error)

$F B=\left(\overline{C_{o}}-\overline{C_{p}}\right) /\left(0.5\left(\overline{C_{o}}+\overline{C_{p}}\right)\right)$ (Fractional Bias)

$F S=2\left(\sigma_{o}-\sigma_{p}\right) /\left(\sigma_{o}+\sigma_{p}\right)$ (Fractional Standard Deviation)

$R=\overline{\left(C_{o}-\overline{C_{o}}\right)\left(C_{p}-\overline{C_{p}}\right)} / \sigma_{o} \sigma_{p}$ (Correlation Coeficient)

$F A 2=0.5 \leq C_{o} / C_{p} \leq 2$ (Factor 2)

where $C$ is the analyzed quantity (concentration) and the subscripts " $o$ " and " $p$ " represent the observed and the predicted values, respectively. The overbars in statistical indices indicate averages. The statistical index FB indicates if the predicted quantity underestimates or overestimates the observed one. The statistical index NMSE represents the quadratic error of the predicted quantity in relation to the observed one. The statistical index FS indicates the measure of the comparison between predicted and observed plume spreading. The statistical 

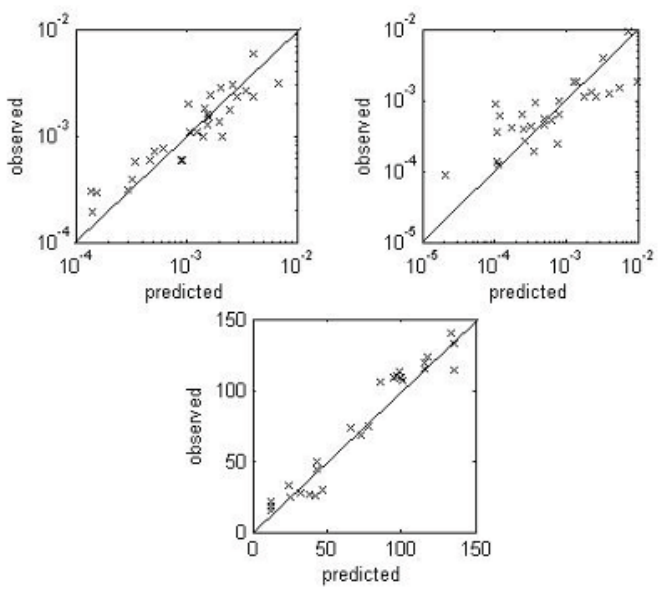

Fig. 6. Plot of (a) concmax, (b) top5 and (c) Sy calculated with SCLE model utilizing the Hanna (1982) turbulence parameterization. X-axis shows predicted values whereas observed values are on the Y-axis.

index FA2 provides the fraction of data for which $0.5 \leq \mathrm{C}_{\mathrm{o}} / \mathrm{C}_{\mathrm{p}} \leq 2$. As nearest zero are the NMSE, FB and FS and as nearest one are the R and FA2, better are the results.

Analyzing the results shown in Table 1, it is possible to infer that the SCLE model employing the meandering parameterization developed in this study reproduces well the experimental data in stable meandering conditions. Furthermore, the SCLE model with these meandering enhanced dispersion parameterizations presents results comparable or even better than ones obtained by other models. Therefore, the proposed parameterizations for the meandering phenomenon reported in the present analysis generate magnitudes of the statistical indices that are within acceptable ranges, with NMSE, FB and FS values relatively near to zero and $\mathrm{R}$ and FA2 relatively near to 1 .

\begin{tabular}{|c|c|c|c|c|c|}
\hline & NMSE & R & FA2 & FB & FS \\
\hline SCLE model Degrazia et al. (2000) & 0.19 & 0.88 & 0.89 & -0.054 & -0.21 \\
SCLE model Hanna (1982) & 0.35 & 0.78 & 0.90 & -0.038 & -0.22 \\
Sagendorf and Dickson (1974) & 0.60 & 0.42 & 0.80 & 0.06 & - \\
Sharan and Yadav (1998) & 0.53 & 0.55 & 0.60 & -0.02 & - \\
Oettl et al. (2001) & 0.21 & 0.86 & 0.87 & -0.13 & - \\
\hline
\end{tabular}

Table 1. Statistical evaluation considering other for the INEL experiment.

\section{Conclusions}

The investigation deals with contaminants dispersion associated with the low wind speed cases. In low wind velocity conditions in the stable PBL, the meandering horizontal of the wind is a physical mechanism that dominates the horizontal spread of contaminants. This means that as the average wind speed decreases, large horizontal low frequency oscillations start to control the flow field, surpassing both the transport and the small-scale diffusion 
ge-nerated by the fully developed turbulence. Therefore, based on meandering phenomenon observational evidences and Degrazia et al. (2000) and Hanna (1982) turbulence approach, which allows to calculate local (at distinct-heights) horizontal Lagrangian time scales, para-meterizations for the reinforced meandering diffusion were derived and presented.

The parameters $\mathrm{p}$ and $\mathrm{q}$ (Eqs. 2 and 3 ) are important quantities describing the meandering phenomenon. They are defined in terms of $\mathrm{m}$, which controls the magnitude of negative lobes in the meandering observed autocorrelation functions, and of the local horizontal time scales $\mathrm{T}_{\mathrm{Lu}, \mathrm{v}}$ for a fully developed turbulence. Therefore, Eq. (9) is a formulation for the meandering parameterization that is described in terms of the meandering period $\mathrm{T}_{*}$ and of the time scales $T_{\mathrm{Lu}, \mathrm{v}}$. Concerning to the $\mathrm{T}_{*}$, an observed representative mean value of the meandering period of the order of $\mathrm{T}_{*}=2000 \mathrm{~s}$, obtained from a large number of experimental data, was employed in this study. This phenomenological choice for the value of $\mathrm{T}_{*}$, allows that the present approach can be applied to meandering distinct cases. On the other hand, the parameterization of $\mathrm{T}_{\mathrm{Lu}, \mathrm{v}}$ was obtained from Degrazia et al. (2000) and Hanna (1982) turbulence descriptions. Thusly, the equations that provide $\mathrm{T}_{\mathrm{Lu}, \mathrm{v}}$ (Eqs. 11, 14 and 15) are expressed in terms of a similarity theory describing the shear dominated stable turbulence.

The meandering parameterizations above discussed were evaluated and tested through the comparison with observational data and other different meandering dispersion models. The results generated by the simulations using the two coupled Langevin equations (SCLE), employing the new parameterizations, agree well with the experimental data, pointing that the present approaches reproduce the contaminants meandering spread process adequately in low wind speed stable conditions.

Finally, considering the good agreement between the results of the proposed model with the experimental ones, the new parameterizations for the meandering phenomenon employed in the SCLE are found to be suitable to simulate meandering enhanced dispersion of contaminants in a low wind speed stable PBL.

\section{Acknowledgement}

The authors acknowledgement the financial support provided by CAPES (Coordenação de Aperfeiçoamento de Pessoal de Nível Superior) and CNPq (Conselho Nacional de Desenvolvimento Científico e Tecnológico).

\section{References}

Anfossi, D.; Alessandrini, S.; Trini Castelli, S.; Ferrero, E.; Oettl, D. \& Degrazia, G. (2006). Tracer dispersion simulation in low wind speed conditions with a new 2D Langevin equation system, Atmospheric Environment, Vol. 40, pp. 7234-7245.

Anfossi, D.; Oettl, D.; Degrazia, G. \& Goulart, A. (2005). An analysis of sonic anemometer observations in low wind speed conditions, Boundary-Layer Meteorology, Vol. 114, pp. 179-203.

Brusasca, G.; Tinarelli, G. \& Anfossi, D. (1992). Particle model simulation of diffusion in low wind speed stable conditions, Atmospheric Environment, Vol. 26A, pp. 707-723.

Carvalho, J.C.; Degrazia, G.A.; Vilhena, M.T.; Magalhães, S.G.; Goulart, A.; Anfossi, D.; Acevedo, O.C. \& Moraes, O.L.L. (2006). Parameterization of meandering phenomenon in a stable atmospheric boundary layer, Physica A, Vol. 368, pp. 247-256. 
Caughey, S.J. (1982). Observed characteristics of the atmospheric boundary layer. In: Nieuwstadt, F.T.M., van Dop, H. (Eds.), Atmospheric Turbulence and Air Pollution Modelling, Reidel, pp. 107-158, Dordrecht.

Caughey, S.J. \& Palmer, S.G. (1979). Some aspects of turbulence structure thought the depth of the convective boundary layer, Quarterly Journal of the Royal Meteorological Society, Vol. 105, pp. 811-827.

Chandrasekhar, S. (1943). Stochastic Problems in Physics and Astronomy, Review of Modern Physics, Vol. 15, pp.1-89.

Champagne, F.H.; Friehe, J.C.; La Rue, J.C. \& Wyngaard, J.C. (1977). Flux measurements, flux estimation techniques, and fine-scale turbulence measurements in the unstable surface layer over land, Journal of Atmospheric Science, Vol. 34, pp. 515-530.

Carvalho, J.C.; Anfossi, D.; Castelli, S.T. \& Degrazia, G.A. (2002). Application of a model system for the study of transport and diffusion in complex terrain to the TRACT experiment, Atmospheric Environment, Vol. 36, pp. 1147-1161.

Cirillo, M.C. \& Poli, A.A. (1992). An intercomparison of semiempirical diffusion models under low wind speed, stable conditions, Atmospheric Environment, Vol. 26A, pp. 765-774.

Csanady, G.T. (1992). Turbulent diffusion in the environment, Geophysics and Astrophysics Monographs, Reidel, 248pp, Boston.

Degrazia, G.A.; Anfossi, D.; Carvalho, J.C.; Mangia, C.; Tirabassi, T. \& Campos Velho, H.F. (2000). Turbulence parameterization for PBL dispersion models in all stability conditions, Atmospheric Environment, Vol. 34, pp. 3575-3583.

Dosio, A.; Guerau de Arellano, J.V. \& Holtslag, A.A.M. (2005). Relating Eulerian e Lagrangian statistics for the turbulent dispersion in the Atmospheric Convective Boundary Layer, Journal of the Atmospheric Sciences, Vol. 62, No. 4, pp. 1175-1191.

Ferrero, E. \& Anfossi, D. (1998). Comparison of FDPs, closure schemes and turbulence parameterizations in Lagrangian stochastic models, International Journal of Environment and Pollution, Vol. 9, pp. 384-410.

Frenkiel, F.N. (1953). Turbulent diffusion: mean concentration distribution in a flow field of homogeneous turbulence, Advances in Applied Mechanics, Vol. 3, pp. 61-107.

Gardiner, C.W. (1997). Handbook of stochastic methods, Springer, 442pp, Berlin.

Goulart, A.; Degrazia, G.A.; Acevedo, O.C. \& Anfossi, D. (2007). Theoretical considerations of meandering winds in simplified conditions, Boundary-Layer Meteorology, Vol. 125, pp. 279-287.

Hanna, S.R. (1989). Confidence limits for air quality model evaluations, as estimed by Bootstrap and Jacknife Resampling Methods, Atmospheric Environment, Vol. 23, pp. 1385-1398.

Hanna, S.R. (1982). Applications in air pollution modelling, In: Atmospheric Turbulence and Air Pollution Modelling, Nieuwstadt, F.T.M., van Dop, H., Reidel, page numbers (275-310), Dordrecht.

Hanna, S.R. (1981). Lagrangian and Eulerian time-scale relations in the daytime boundary layer, Journal of Applied Meteorology, Vol. 20, pp. 242-249.

Hanna, S.R. (1968). A method of estimating vertical eddy transport in the planetary boundary layer using characteristics of the vertical velocity spectrum, Journal of the Atmospheric Sciences, Vol. 25, pp. 1026-1033. 
Irwin, J.S. (1979). Estimating plume dispersion - a recommended generalized scheme. Preprints fourth symposium on turbulence, diffusion and air pollution, American Meteorological Society, 45 Beacon Street, Boston, Mass. 02108, pp. 62-69.

Kaimal, J.C. (1976). Turbulence structure in the convective boundary layer, Journal of Atmospheric Science, Vol. 33, pp. 2152-2169.

Nieuwstadt, F.T.M. (1984). The turbulent structure of the stable, Nocturnal Boundary Layer, Journal of the Atmospheric Sciences, Vol. 41, No. 14, pp. 2202-2216.

Oettl, D.; Almbauer, R.A. \& Sturm, P.J. (2001). A new method to estimate diffusion in stable, low-wind conditions, Journal of Applied Meteorology, Vol. 40, pp. 259-268.

Oettl, D.; Goulart, A.; Degrazia, G.A. \& Anfossi, D. (2005). A new hypothesis on meandering atmospheric flows in low wind speed conditions, Atmospheric Environment, Vol. 39, pp. 1739-1748.

Olesen, H.R.; Larsen, S.E. \& Hojstrup, D. (1984). A new hypothesis on meandering atmospheric flows in low wind speed conditions, Atmospheric Environment, Vol. 39, pp. 1739-1748.

Panofsky, H.A.; Tennekes, H.; Lenschow, D.H. \& Wyngaard, J.C. (1977). The characteristics of turbulent velocity components in the surface layer under convective conditions, Boundary-Layer Meteorology, Vol. 11, pp. 355-361.

Rodean, H.C. (1996). Stochastic Lagrangian Models of Turbulence Diffusion, American Meteorological Society, 84pp, Boston.

Sagendorf, J.F. \& Dickson, C.R. (1974). Diffusion under low wind speed, inversion conditions, NOAA Technical Memorandum ERL ARL-52, 89pp.

Sharan, M. \& Yadav, K. (1998). Simulation of diffusion experiments under light wind, stable conditions by a variable k-theory model, Atmospheric Environment, Vol. 32, pp. 3481-3492.

Sharan, M.; Yadav, K. \& Sing, M.P. (1995). Comparison of sigma schemes for estimation of air pollutant dispersion in low winds, Atmospheric Environment, Vol. 29, pp. 2051-2059.

Sorbjan, Z. (1989). Structure of the Atmospheric Boundary Layer, Prentice-Hall, Englewood Cliffs, NJ, 317pp.

Thomson, D.J. (1987). Criteria for the selection of stochastic models of particle trajectories in turbulent flows, Journal of Fluids Mechanics, Vol. 180, pp. 529-556.

Wang, M.C. (1945). Influence of magnetic field on the Brownian motion of charged particle, Journal of the Physical Society of Japan, Vol. 28, pp. 559-564.

Wilson, J.D. \& Sanford, B.L. (1996). Review of Lagrangian stochastic models for trajectories in turbulent atmosphere, Boundary-Layer Meteorology, Vol. 78, pp. 191-210.

Wilson, R.B.; Start, G.E.; Dickson, C.R. \& Ricks, N.R. (1976). Diffusion under low wind speed conditions near Oak Ridge, Tennessee, NOAA Technical Memorandum ERL ARL-61, 83pp.

Wyngaard, J.C.; Coté, O.R. \& Rao, K.S. (1974). Modelling of the atmospheric boundary layer Advances in Geophysics, Academic Press, Vol. 18A, pp. 193-212, New York.

Yeung, P.K. (2002). Lagrangian investigations of turbulence, Annual Review of Fluid Mechanics, Vol. 34, pp. 115-142.

Zannetti, P. (1990). Air Pollution Modeling. Teories, Computational Methods and Available Software, Kluwer Academic Publisher, 444pp, New York. 
Zilitinchevick, S.S. (1972). On the determination of the height of the Ekman boundary layer, Boundary-Layer Meteorology, Vol. 3, pp. 141-145. 


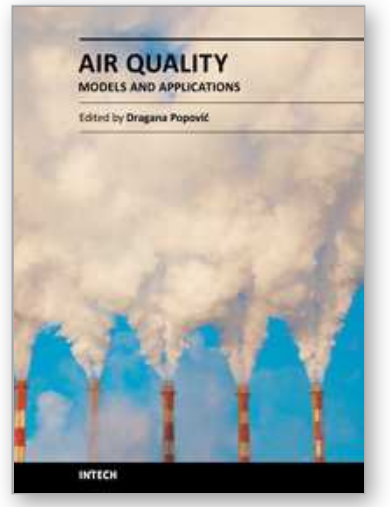

\author{
Air Quality-Models and Applications \\ Edited by Prof. Dragana Popovic
}

ISBN 978-953-307-307-1

Hard cover, 364 pages

Publisher InTech

Published online 09, June, 2011

Published in print edition June, 2011

Air pollution has been a major transboundary problem and a matter of global concern for decades. High concentrations of different air pollutants are particularly harmful to large cities residents, where numerous anthropogenic activities strongly influence the quality of air. Although there are many books on the subject, the one in front of you will hopefully fulfill some of the gaps in the area of air quality monitoring and modeling, and be of help to graduate students, professionals and researchers. The book is divided in five sections, dealing with mathematical models and computing techniques used in air pollution monitoring and forecasting; air pollution models and application; measuring methodologies in air pollution monitoring and control; experimental data on urban air pollution in China, Egypt, Northeastern U.S, Brazil and Romania; and finally, the health effects due to exposure to benzene, and on the influence of air pollutants on the acute respiratory diseases in children in Mexico.

\title{
How to reference
}

In order to correctly reference this scholarly work, feel free to copy and paste the following:

Gervasio A. Degrazia, Andrea U. Timm, Virnei S. Moreira and Debora R. Roberti (2011). Meandering Dispersion Model Applied to Air Pollution, Air Quality-Models and Applications, Prof. Dragana Popovic (Ed.), ISBN: 978-953-307-307-1, InTech, Available from: http://www.intechopen.com/books/air-quality-models-andapplications/meandering-dispersion-model-applied-to-air-pollution1

\section{INTECH}

open science | open minds

\section{InTech Europe}

University Campus STeP Ri

Slavka Krautzeka 83/A

51000 Rijeka, Croatia

Phone: +385 (51) 770447

Fax: +385 (51) 686166

www.intechopen.com

\section{InTech China}

Unit 405, Office Block, Hotel Equatorial Shanghai

No.65, Yan An Road (West), Shanghai, 200040, China 中国上海市延安西路65号上海国际贵都大饭店办公楼 405 单元

Phone: +86-21-62489820

Fax: $+86-21-62489821$ 
(C) 2011 The Author(s). Licensee IntechOpen. This chapter is distributed under the terms of the Creative Commons Attribution-NonCommercialShareAlike-3.0 License, which permits use, distribution and reproduction for non-commercial purposes, provided the original is properly cited and derivative works building on this content are distributed under the same license. 